\title{
Geometry effect on the estimation of band reflectance in an urban area
}

\author{
C. M. Frey • E. Parlow
}

Received: 31 July 2007 / Accepted: 10 July 2008 / Published online: 14 August 2008

(C) Springer-Verlag 2008

\begin{abstract}
Reflectance of the urban surface is an important factor for urban climate studies and can be assessed using standard remote sensing applications. However, no application considers the three-dimensional structure of the city surface and its resulting shading patterns or the inclined roof surfaces. To determine the effect of these factors on the estimation of urban surface reflectance, a high-resolution raster-based city-surface model was used to estimate the spatial solar irradiance in an example city, namely Basel in Switzerland. Eight times daily for 1 year, the solar irradiance was calculated using MODTRAN and the illumination geometry of the city. Subsequently, the spatial distribution of the solar irradiance, as well as the error in assumed reflectance values were analysed. The error in estimation of reflectance increased with lower solarelevation angle, so its maxima were found in winter. Higher visibility of the assumed atmosphere also increased the estimated error due to the lower proportion of diffuse irradiance. The error decreased with coarser spatial resolution of the pixel.
\end{abstract}

\section{Introduction}

The albedo is an important parameter for urban climate studies. It determines how much incoming solar irradiation is absorbed by the surface and is made available for other energy fluxes. It is often assessed using remote-sensing methods (Brest 1987; Sailor 1995; Taha 1997). In this

C. M. Frey $(\bowtie) \cdot$ E. Parlow

Institute for Meteorology, Climatology and Remote Sensing,

Department of Geosciences, University of Basel,

Klingelbergstrasse 27,

4056 Basel, Switzerland

e-mail: corinne.frey@unibas.ch context, among the most commonly used satellites are the ASTER (Advanced Spaceborne Thermal Emission and Reflection Radiometer), the LANDSAT TM and ETM+ and also the SPOT sensor (Satellite Pour l'Observation de la Terre) (Chrysoulakis 2003; Frey et al. 2007; Hafner and Kidder 1999; Small 2005; Soler and Ruiz 1994). Singleband albedos are often directly derived from top of the atmosphere radiances using look up tables (LUTs) containing information about the composition of the atmosphere, which is done, for example, for the ASTER surfacereflectance product (NASA 2007a). Elsewhere, the albedos are calculated by building a ratio between otherwise corrected image radiances and the modelled solar irradiance, as proposed in the LANDSAT handbook (NASA 2007b). Some groups used digital elevation models for the correction of the spatial irradiance due to topographic effects of the terrain (Parlow 1996; Rigo and Parlow 2007).

Estimating the albedo from space always means compromising, as the spatial resolution of the sensor is too large to optimally resolve the observed features in many cases. The pixels are a mixture between different features and surface materials. Therefore, the albedo of urban areas is strongly determined by the urban setting. Urban areas can be characterised by their geometrical structure. They consist of a mixture of houses, blocks and streets of different forms and sizes on one hand, and of diverse surface materials on the other hand. In between, urban vegetation occurs, modifying the urban climate through its altered surface characteristics. Additionally to this effect the three-dimensional geometry of cities has an impact on the estimation of the urban albedo. Solar irradiation impinges on various surface inclinations, defined by the roof's slopes and aspects. Shading effects lead to very dark surfaces, lowering the satellite estimated albedo considerably. Neither of the approaches accounts for the effect of these urban settings. 
A literature survey shows that some research has been conducted in this field already. Aida (1982a) analysed the relation between urban albedo and the solar zenith angle using a model experiment with concrete blocks in cubic form. Aida and Gotoh (1982b) deepened their understanding using a two-dimensional urban block-canyon array model. They showed that the urban albedo is low when the solar zenith angle is also low. Kondo et al. (2001) showed the same, using a modelling approach with simplified threedimensional buildings of equal size, arranged in a regular lattice. Both groups modelled the albedo very accurately and described its behaviour with changing environmental parameters. However, they did not analyse the resulting magnitude of the error in albedo estimation, while ignoring the fact of the urban setting. Finally, Sailor and Fan (2002) used Monte Carlo style simulations with different urban land-use classes for describing the diurnal variability of the effective albedo for cities and they included the effects of shading. Analysing their computed transects of reflectance, they found that the nadir-view-albedo underestimates daily solar radiative loads by $11-22 \%$.

From the discussion of shadows in the urban setting, it seems to be reasonable to distinguish between 'local' and 'regional' albedo. Local albedo on one hand means the reflectivity of the surface as it is. It is the reflectivity from a single-surface material. The regional albedo on the other hand includes effects from a broader environment and may include different surface materials and forms, as well as shading effects (compare Schwander et al. 1999).

This analysis shall be a further step in the understanding of the urban albedo pattern. It aims to analyse if there is a significant geometry effect on the reflectance estimation for the sample urban area, Basel. Mainly the effect of shading from buildings and constructions at different solar elevation angles and different atmospheric states shall be analysed. To this end, several scenarios are modelled using a radiative transfer model and simple geometric relations as discussed in section Estimation of spatial irradiance and single-band albedo. The results of this pure modelling study are statistically analysed and presented. The results are also aggregated towards increasingly coarser spatial resolutions to see at which ground resolution the pixel shading effects cease to have influence. All the modelling assumes that the satellite acquisition would be only nadir-viewing.

\section{Study area}

Study area is Basel, a city with about 200 '000 inhabitants. Basel is situated in the north-western corner of Switzerland at the bend of the River Rhine. The River Rhine is the natural border to Germany (Baden-Württemberg) in the north. In the west, the city of Basel is bordered by France
(Alsace). Basel is a typical European mid-latitude city with building types ranging from detached houses to blocks and skyscrapers. It includes an old commercial inner city, modern business districts, industrial areas as well as various residential areas on different socio-economic levels.

Basel area was chosen, because it is a representative urban site in the centre of Europe and the urban climate project BUBBLE, the Basel-Urban-Boundary-Layer-Experiment, an international joint research activity, was carried out in Basel offering a unique archive of measured micrometeorological data (Rotach et al. 2005). Basel features typical mid-European urban characteristics; therefore, the approach used in this research can be used also for other mid-European cities.

\section{Data}

A digital city surface model of Basel was used. The model was obtained from the authorities of the Grundbuch- und Vermessungsamt in Basel, Switzerland. A vector-to-raster conversion had to be performed, before using the model. The resulting raster model has a spatial resolution of $1 \mathrm{~m}$ and depicts the buildings of the inner city of Basel without vegetation. The model height is absolute; the Earth surface is considered to be zero. The vertical step height of the model is $1 \mathrm{~m}$.

Furthermore, a QUICKBIRD image was used for the discrimination of urban vegetation. QUICKBIRD is a commercial satellite for Earth observation from DigitalGlobe that is operated in the panchromatic with $60-\mathrm{cm}$ spatial resolution and in the multispectral mode with $2.4 \mathrm{~m}$ spatial resolution. Four spectral channels (blue, green, red and near-infrared) are available in the multispectral mode. The city surface model was geo-located with this QUICKBIRD image of the same area to enable joint analysis.

\section{Estimation of spatial irradiance and single-band albedo}

In the following section, the methods of this analysis are presented. The albedo is defined in the first subsection, while the second section contains the equations for the geometric relations that use various irradiance terms. Finally, in the third section, the modelling of these single irradiance terms is explained and some comparisons with real measured data are made.

\subsection{Definition of albedo}

The spatial surface single-band albedo in the wavelength range from $\lambda_{1}$ to $\lambda_{2}$ is defined as a measure of the fraction 
of radiance reflected from a surface compared to the solar irradiance within the same wavelength range:

$\rho(\Delta \lambda)=\frac{L_{r}(\Delta \lambda)}{L_{g}(\Delta \lambda)}$

$\rho \quad$ Single-band surface albedo from $\lambda_{1}$ to $\lambda_{2}$

$L_{\mathrm{r}} \quad$ Irradiance reflected from the Earth surface and integrated from wavelength $\lambda_{1}$ to $\lambda_{2}\left[\mathrm{Wm}^{-2} \mathrm{sr}^{-1} \mu \mathrm{m}^{-1}\right]$

$L_{g} \quad$ Global irradiance, integrated from wavelength $\lambda_{1}$ to $\lambda_{2}$ (beam plus diffuse irradiance) $\left[\mathrm{Wm}^{-2} \mathrm{sr}^{-1} \mu \mathrm{m}^{-1}\right]$

$\Delta \lambda$ Wavelength range from $\lambda_{1}$ to $\lambda_{2}$

The estimation of the albedo, using this typically applied approach, is done without considering the spatial heterogeneity of the irradiation. However, the global irradiation is dependent on the sun-surface geometry and considerable variations can be observed, especially in mountainous terrain as well as in urban areas (Parlow 1998). The single-band albedo in the spatial domain is therefore calculated best using spatially distributed irradiance values. In the following, the term single-band albedo is addressed simply as albedo.

It is important to find out at what height the involved irradiance terms are modelled or measured. If the considered heights are just above the surface, then the resulting albedo belongs to the local surface type and the albedo can be referred to as a local albedo (Christen and Vogt 2004). However, if the measurement is high enough to "see" different local surface types, then one may address the resulting albedo as regional albedo.

\subsection{Geometric relations}

The solar irradiance of a spectral band is given as the sum of beam irradiance, diffuse irradiance, and irradiance reflected from the environment (adjacency effects) of this spectral band.

$$
L_{g_{-} \text {sunlit }}(x, y)=L_{b} \cdot \cos \alpha(x, y)+L_{d} \cdot \operatorname{svf}(x, y)+L_{r}(x, y)
$$

$$
\begin{array}{ll}
\alpha & \begin{array}{l}
\text { Illumination angle [ } \left.{ }^{\circ}\right] \\
L_{\mathrm{g}_{\_} \text {sunlit/shaded }}
\end{array} \\
& \begin{array}{l}
\text { Global irradiance in sunlit or shaded area, } \\
\text { integrated from wavelength } \lambda_{1} \text { to } \lambda_{2}
\end{array} \\
& {\left[\mathrm{Wm}^{-2} \mathrm{sr}^{-1} \mu \mathrm{m}^{-1}\right]} \\
L_{\mathrm{b}} & \begin{array}{l}
\text { Beam irradiance, integrated from } \\
\text { wavelength } \lambda_{1} \text { to } \lambda_{2}\left[\mathrm{Wm}^{-2} \mathrm{sr}^{-1} \mu \mathrm{m}^{-1}\right]
\end{array} \\
& \begin{array}{l}
\text { Diffuse irradiance, integrated from } \\
L_{\mathrm{d}}
\end{array} \\
& \begin{array}{l}
\text { wavelength } \lambda_{1} \text { to } \lambda_{2}\left[\mathrm{Wm}^{-2} \mathrm{sr}^{-1} \mu \mathrm{m}^{-1}\right] \\
L_{\mathrm{r}}
\end{array} \\
& \text { Irradiance reflected from the environment, } \\
& \text { integrated from wavelength } \lambda_{1} \text { to } \lambda_{2} \\
& {\left[\mathrm{Wm}^{-2} \mathrm{sr}^{-1} \mu \mathrm{m}^{-1}\right]}
\end{array}
$$

svf $\quad$ Sky view factor $(0-1)$

In shaded areas the beam radiation is dismissed and the equation is:

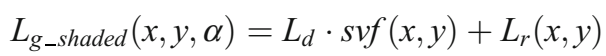

The expression of the diffuse irradiance was taken from Liu and Jordan (1963) and Hofierka and Šúri (2002).

The global irradiance is dependent on the illumination angle (the solar zenith relative to the Earth surface and azimuth angle relative to a given direction, here east of north) as seen in Eq. 2. In case of horizontal surface this angle is simply the solar zenith angle. In case of an inclined surface, the illumination angle can be calculated as (Liu and Jordan 1963; Iqbal 1983; Chrysoulakis et al. 2004):

$$
\begin{aligned}
\cos \alpha(x, y)= & \cos \Theta_{s} \cdot \cos \Theta_{n}(x, y)+\sin \Theta_{s} \\
& \cdot \sin \Theta_{n}(x, y) \cdot \cos \left\{\Phi_{s}-\Phi_{n}(x, y)\right\}
\end{aligned}
$$

\section{$\Theta_{\mathrm{s}} \quad$ Solar zenith angle $\left[{ }^{\circ}\right]$}

$\Theta_{\mathrm{n}} \quad$ Terrain slope $\left[{ }^{\circ}\right]$

$\Phi_{\mathrm{s}} \quad$ Solar azimuth angle $\left[{ }^{\circ}\right]$, (east of north)

$\Phi_{\mathrm{n}} \quad$ Aspect or topographic azimuth [ $\left.{ }^{\circ}\right]$, (east of north)

The terrain slope $\left(\Theta_{\mathrm{n}}\right)$ and the topographic azimuth $\left(\Phi_{\mathrm{n}}\right)$ have to be calculated separately. The topographic azimuth was estimated using a routine in the topographic modelling menu of the digital image analysis software package ENVI. The terrain slope could also be calculated in this menu; however, for the city surface model, the ENVI routine is not applicable, as it includes the building walls in its calculations and it does not consider small-scale changes. Therefore, a separate routine was developed, which accounts only for the slopes on the rooftops.

The irradiance reflected from the environment is calculated using following parameterisation:

$L_{r}(x, y)=L_{g}(x, y) \cdot \rho_{s}(x, y) \cdot(1-\operatorname{svf}(x, y))$

$\rho_{\mathrm{s}} \quad$ Smoothed albedo of the Earth surface

$L_{\mathrm{g}}$ Global irradiance, integrated from wavelength $\lambda_{1}$ to $\lambda_{2}$ $\left[\mathrm{Wm}^{-2} \mathrm{sr}^{-1} \mu \mathrm{m}^{-1}\right]$. Corresponds to the term $L_{\mathrm{g}_{-} \text {sunlitshaded }}$ of Eq. 2

The reflected irradiance term stands for the radiation that is reflected by the environment of the pixel and is calculated iteratively. A first estimate of the global irradiance (Eqs. 3 and 4) is used to calculate the reflected irradiance, which is then used to update the global irradiance. This process is repeated several times. The used albedo (the top of the atmosphere albedo) was smoothed first for usage in the adjacency-effects estimation. 
The sky view factor describes the proportion of the upper hemisphere that is 'seen' from a pixel. The sky view factor ranges from from 0 to 1 . It is calculated by a routine, which is adapted from Dozier et al. (1981). First, the routine searches the limiting horizon angle for each pixel and for a given set of directions (36 directions resulting in degree steps of $10^{\circ}$ ). The angle is determined by simple trigonometry between the corresponding two pixels. For each pixel, a set of $n$ angles, representing the circular horizon, is determined via this process. This dataset, consisting of number of pixels multiplied by the number of directions elements, is used later for the computation of shaded pixels. Secondly, the routine averages the horizon angles of each pixel. This average represents the horizon view factor (hvf), from which the sky view factor can easily be derived.

Shaded areas have to be determined firstly to calculate the irradiance in the spatial domain. This is done comparing the horizon angle in the direction of the sun azimuth to the solar elevation angle pixel by pixel. If the solar elevation angle is lower than the horizon angle, the pixel is marked as shaded.

\subsection{Estimation of the irradiance terms}

The estimation of the diffuse irradiance can be done using a parameterisation linking the clearness index $\mathrm{c}$ (global irradiance/exo-atmospheric irradiance) with the diffuse fraction (diffuse irradiance/global irradiance). For example the parameterisation from Erbs et al. (1982) is

For $\mathrm{c}<0.22 \mathrm{THEN}_{\mathrm{d}}=(1.0-0.09 * \mathrm{c}) * \mathrm{~L}_{\mathrm{g}}$

For $\mathrm{c}>=0.22$ and for $\mathrm{c}<0.8 \mathrm{~L}_{\mathrm{d}}$

$$
=\left(\begin{array}{r}
0.9511-0.1604 * \mathrm{c}+4.388 *\left(\mathrm{c}^{2}\right) \\
-16.638 *\left(\mathrm{c}^{3}\right)+12.336 *\left(\mathrm{c}^{4}\right)
\end{array}\right) * \mathrm{~L}_{\mathrm{g}}
$$

For $\mathrm{c}>0.8 \mathrm{~L}_{\mathrm{d}}=0.165 * \mathrm{~L}_{\mathrm{g}}$

The beam and diffuse irradiance can then be computed as:

$\mathrm{L}_{\mathrm{b}}=\mathrm{L}_{\mathrm{g}}-\mathrm{L}_{\mathrm{d}}$

$L_{\mathrm{d}} \quad$ Diffuse radiance, integrated from wavelength $\lambda_{1}$ to $\lambda_{2}$ $\left[\mathrm{Wm}^{-2} \mathrm{sr}^{-1} \mu \mathrm{m}^{-1}\right.$ ]

$\mathrm{L}_{\mathrm{b}}$ Beam radiance, integrated from wavelength $\lambda_{1}$ to $\lambda_{2}$ $\left[\mathrm{Wm}^{-2} \mathrm{sr}^{-1} \mu \mathrm{m}^{-1}\right.$ ]

This parameterisation works well around noon but failed in the case of very low sun elevation angle, since in the early morning and the late afternoon the percentage of diffuse irradiance of the global irradiance is very high. Another parameterisation that works similar is from Maxwell (1987).

What is more straightforward, is to take the diffuse irradiance values directly produced by the atmospheric transfer code, in this case MODTRAN (MODerate spectral resolution atmospheric TRANSmittance algorithm and computer model). MODTRAN was developed by AFRL/ VS (The Air Force Research Laboratory, Space Vehicles Directorate) in collaboration with Spectral Sciences, Inc. (Berk et al. 1999). It calculates atmospheric transmission, atmospheric background irradiance, single-scattered solar and lunar irradiance, direct solar and lunar irradiation, and multiple-scattered solar and thermal radiance for any point in the atmosphere and for any path within the atmosphere for frequencies from 0 to $50,000 \mathrm{~cm}^{-1}$.

However, recently the question arose as to whether MODTRAN overestimates the diffuse irradiance (see Halthore and Schwartz 2000; Henzing et al. 2004). Both studies compare in situ measurements of clear sky beam and diffuse irradiation with MODTRAN results, using accurate aerosol surface measurements for model input. While the beam irradiation was modelled well in both studies, the diffuse irradiation was overestimated, in average $25 \mathrm{Wm}^{-2}$ (Henzing et al. 2004). Despite this, MODTRAN results were used for this study. The conclusions from a comparison of MODTRAN results and in situ measured radiances presented in the following explain this choice. Figure 1a shows the global and the diffuse irradiation, measured at the MeteoSuisse station 'Davos' (an alpine station at 1,590 m asl) and 'Payerne' (a lowland station at $491 \mathrm{~m}$ asl) by CM21 sensor from Kipp and Zonen on 14 December 2001.

The solid line shows data of the station 'Davos' on a clear and bright day. In Payerne, there must have been a few translucent clouds, reducing the solar irradiation. The diffuse irradiation amounts for 15 , respectively $30 \%$ of the global irradiation at noon. This example points out that the diffuse irradiation is highly variable, depending on, besides altitudinal effects, the possible atmospheric compositions. The solid lines of Fig. 1b show irradiation values measured by the Institute of Meteorology, Climatology and Remote Sensing of the University of Basel at the urban site 'Sperrstrasse', which is located inside the area of interest of this analysis (Rotach et al. 2005; Christen and Vogt 2004). Two radiation sensors were used for the measurements: a CNR1 from Kipp and Zonen on top of a tower, seeing only the upper hemisphere and a CM11 also from Kipp and Zonen, which was installed inside the street canyon and was shaded during the whole day on 14 December 2001. The dashed lines depict the modelled values, using the already-described procedures and MODTRAN at the same spots where the sensors were installed during the measurements. The MODTRAN standard winter mid-latitude atmospheric profile was used together with the "no aerosol attenuation' option. The curves of course do not agree perfectly as the actual atmospheric profile is not known. However, they show that the parameterisation of the 


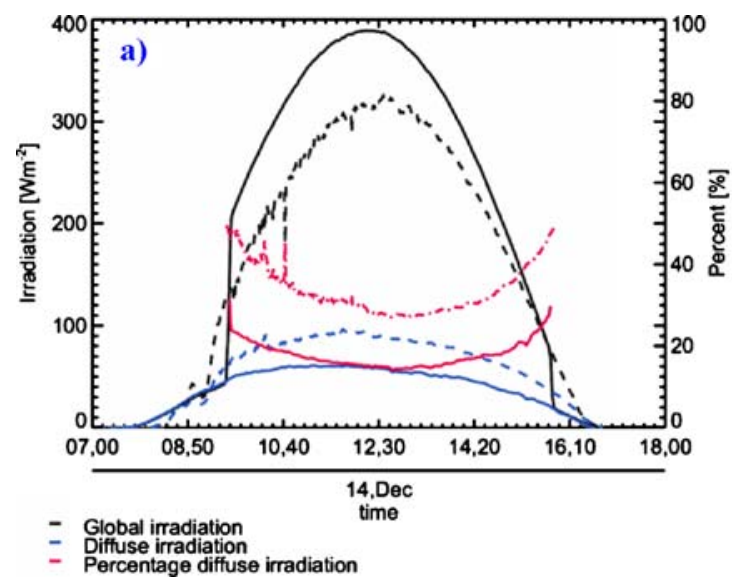

Fig. 1 a Global and diffuse radiation measurement at Davos (solid line) and Payerne (dashed line) (source MeteoSwiss). b Global irradiance during the course of 1 day. The solid line shows the results of the measurement using a CNR. The dashed line shows the

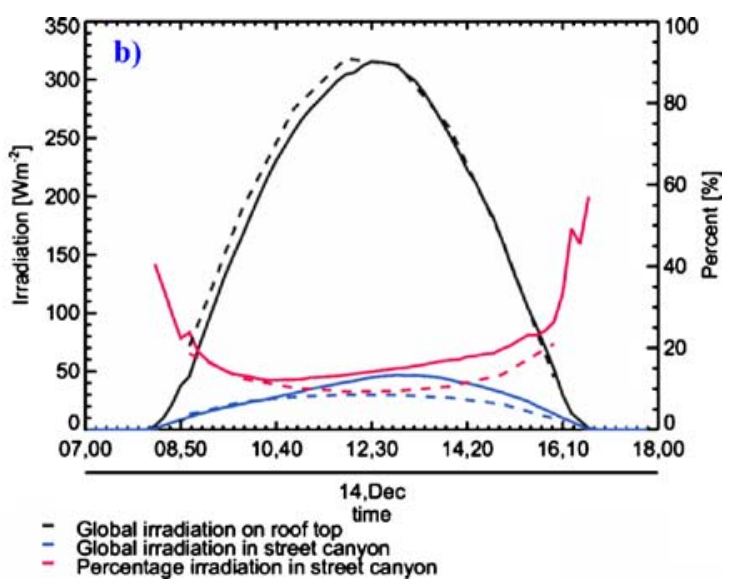

modelling results using a mid-latitude winter atmosphere with no aerosol attenuation. In both figures, the blue line shows the percentage of the diffuse irradiation or the irradiation in the street canyon versus the global irradiation irradiation of the shaded areas lies in an acceptable range. Attention should be paid to the fact that the percentage of diffuse irradiance increases strongly with very low sun elevation angles.

In this paper, diffuse irradiances from MODTRAN are used despite the already-mentioned restrictions, as, firstly, MODTRAN considers the variable percentage of the diffuse part of the global radiation, and, secondly, the modelling does not reproduce real annual patterns, but does, however, assume a fixed standard atmosphere with no clouds. This assumption is necessary, as in optical remote sensing only clear and bright days can be used to estimate the surface albedo. To account for different states of the atmosphere the runs were performed fourfold with different aerosol models (option IHAZE in the MODTRAN model):

1. Urban aerosols, visibility $5 \mathrm{~km}$

2. Rural aerosols, visibility $23 \mathrm{~km}$

3. Only tropospheric aerosols, visibility $50 \mathrm{~km}$

4. No aerosol attenuation

The first assumption stands for a very heavy loaded atmosphere, where the diffuse part of the global irradiance is very high. The third assumption represents extremely clear days with the diffuse part being very small. The second assumption is midway between the other two extremes and may account for most clear and sunny days in Basel. The fourth assumption assumes that there is no attenuation by aerosols. The modelled radiances are applied then to Eqs. 3-5 to distribute them in the spatial domain as described in the section Geometric relations.

The already-described approach of calculating spatial irradiance values is simple and applicable in large areas without requiring much CPU computing time. The spatial irradiance can be calculated easily for large areas to get input data for the modelling of the surface albedo. However, the simplifications of the reflection term may not be optimally suited for urban areas. The reflection term assumes that the surrounding pixels are all equally illuminated. Of course this is not the case as, on the contrary, there might be extremely illuminated and completely shaded walls, contributing to the intensity of the irradiation and therefore also influencing satellite derived albedo products. Their contribution is dependent on the pixel location. A better estimation can be given by ray-tracing models, which are far more complex and elaborate. The disadvantage of these models is the computing time. For large areas like the city of Basel, such an approach is not feasible yet.

In this paper, firstly the spatial distribution of irradiance in the urban area of Basel is analysed for a whole year and 8 times a day at 09:00, 10:00, 11:00, 12:00, 13:00, 14:00, 15:00, and 16:00 hours. For each time slot, the atmospheric transfer code MODTRAN was run and the global irradiance per wave number was extracted, which is the standard output of MODTRAN. Often satellite data are integrated irradiances per micron $\left[\mathrm{Wm}^{-2} \mathrm{sr}^{-1} \mu \mathrm{m}^{-1}\right]$, like, for example, the ASTER images, which are dependent on the spectral response of the sensor. Therefore, the MODTRAN output irradiances were initially converted from irradiances per wave number into irradiances per micron using the following relationship (Schläpfer and Odermatt 2006):

$$
\begin{aligned}
L_{\lambda} & {\left[W m^{-2} s r^{-1} \mu m^{-1}\right]=v^{2}\left[\left(\mathrm{~cm}^{-1}\right)^{2}\right] } \\
\cdot L_{v}\left[W c m^{-2} s r^{-1} \mathrm{~cm}\right] & =v^{2} \cdot L_{v}\left[W m^{-2} s r^{-1} \mu m^{-1}\right]
\end{aligned}
$$


Then the irradiances belonging to band $i$ (here ASTER band 1) were convolved with the spectral response $r$ of the sensor for band $i$, according to the following expression:

$L_{i}=\frac{\int L(\lambda) \cdot r_{i}(\lambda) d \lambda}{\int r_{i}(\lambda) d \lambda} \approx \frac{\sum_{n=\lambda_{1}}^{\lambda_{2}} L\left(\lambda_{n}\right) \cdot r_{i}\left(\lambda_{n}\right) \Delta \lambda_{n}}{\sum_{n=\lambda_{1}}^{\lambda_{2}} r_{i}\left(\lambda_{n}\right) \Delta \lambda_{n}}$

The spectral response for the ASTER band 1 was first interpolated for each wave number using the values available from the ASTER homepage to fit them to the MODTRAN irradiance output. Secondly, an image with local albedos was created. The albedos were determined according to the land use of the pixel. The classes 'roof', 'street', 'vegetation' and 'water' were determined using the city-surface model and the NDVI (normalised difference vegetation index) from the QUICKBIRD image. This image refers to the local albedos as measured at the ground surface. For the roof class, the value of 0.15 was applied; for street, 0.07 ; for 'vegetation', 0.1 ; and for 'water', 0.05 . Using this image, the reflected irradiance was estimated using the spatial irradiance and the local albedos. This reflected irradiance was later used for the assessment of the error in albedo estimation. The NDVI was calculated using band 3 and band 4 from QUICKBIRD. Attention should be paid to the fact, that the local albedos consider only the surfaces seen from nadir view. Other parts, which also form part of the city surface, like walls, are not included in this analysis.

The estimated albedos were computed as the ratio between the before mentioned reflected irradiances and one single value for the global irradiance: the irradiance on a horizontal plane. These modelled 'regional' albedos stand for the albedo as calculated using satellite images for inputnot taking into account the spatial structure of the city.

\section{Results}

The results of this analysis are presented in two ways: first, the results of the spatial irradiance modelling is examined; and, secondly, the consequences of this modelling on the albedo estimation are presented.

\subsection{Modelling of spatial irradiance}

The spatial irradiance shows very strong spatial patterns in the urban area. The irradiance of shaded pixels consists only of the reflected and diffuse part, which is quite low, compared to fully sunlit pixels. Highest absolute differences between the pixels of the image are found on summer days, as the solar irradiation is very strong during this time. Very high differences are also found in winter when the sun altitude is very low and shadows are the largest. Figure 2 shows the spatial irradiance of a part of the city surface model on 12 June 2001 at the 8 time steps of modelling using the rural aerosol model of MODTRAN with visibility of $23 \mathrm{~km}$. While the scenes around midday are very bright with only small parts shaded, the morning and early evening scene features long dark shadows. The images highlight the effect of inclined rooftops. Rooftops facing the sun are the brightest spots in the images, while the opposite rooftops have much lower irradiance values, even if they are not shaded.

The average differences of the whole area of the city surface model depend on the time and day of the year.
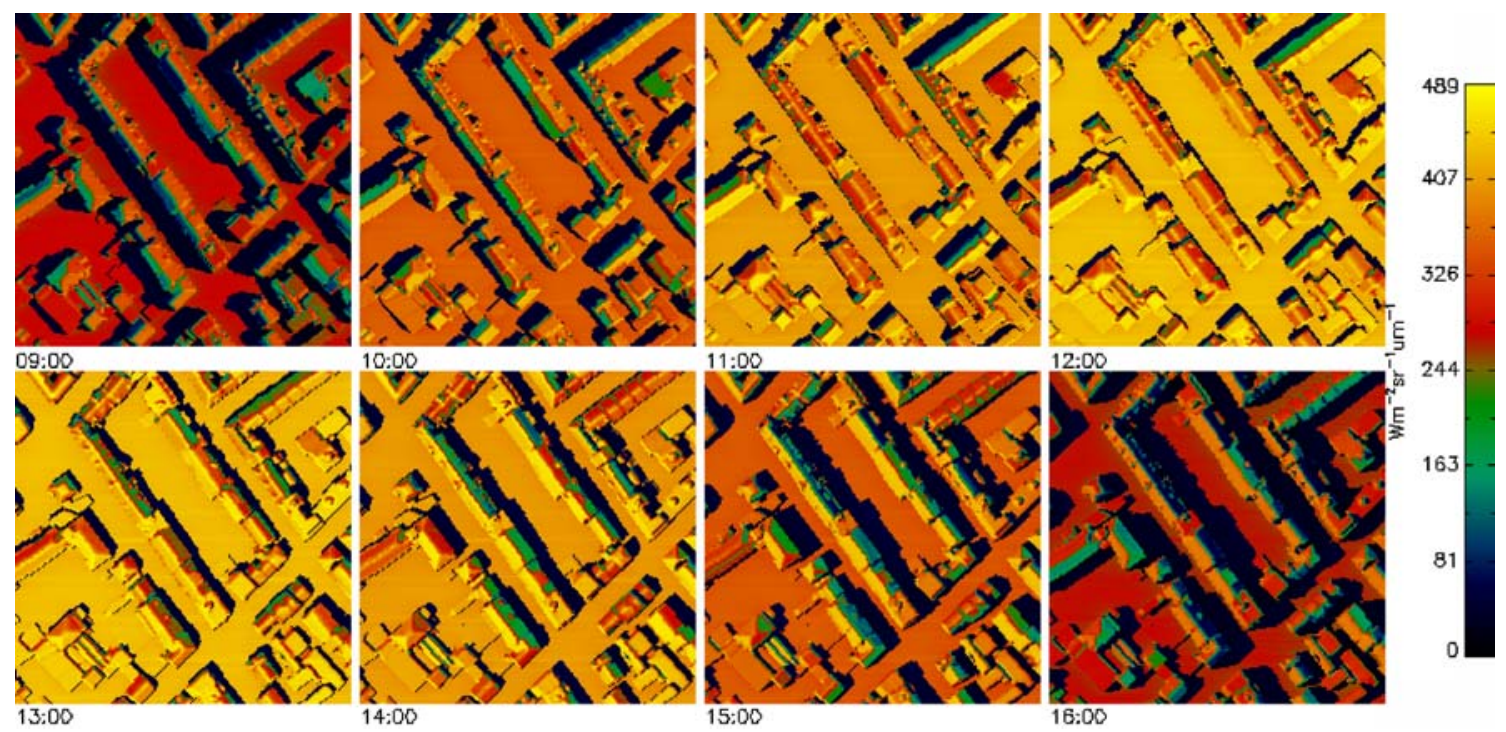

Fig. 2 Small section of the city surface model, showing the incoming irradiance $\left[\mathrm{Wm}^{-2} \mathrm{sr}^{-1} \mu \mathrm{m}^{-1}\right.$ ] from 12 June 2001, convolved for ASTER band 1 . The model was run with the rural standard atmosphere, $23 \mathrm{~km}$ visibility 

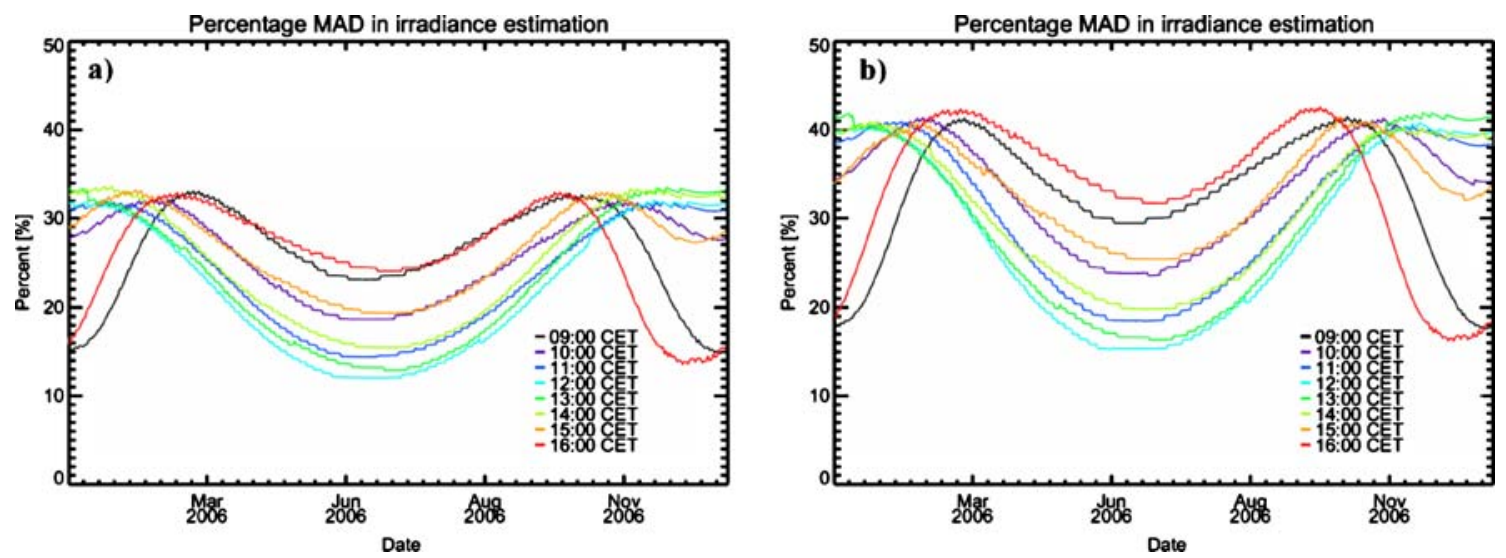

Fig. 3 Percentage of absolute mean error in irradiance estimation of the irradiance on a horizontal plane with the rural aerosol model, visibility $23 \mathrm{~km}$. a From the whole city surface model, b from a selected densely built-up area

Figure 3 shows the average differences of the modelled irradiance to the irradiance incident on a horizontal plane in a rural atmosphere, $23 \mathrm{~km}$ visibility - in percentage of the irradiance incident on a horizontal plane. The differences are defined as the absolute mean difference (MAD) and are calculated as follows:

$M A D=\frac{1}{n} \sum_{i=1}^{n}\left(\left|L_{g_{-} \text {mean }}-L_{g_{i}}\right|\right)$

\section{MAD Mean absolute difference}

$L_{\mathrm{g}_{-} \text {mean }}$ Mean of the spatial distributed global irradiance, integrated from wavelength $\lambda_{1}$ to $\lambda_{2}$ $\left[\mathrm{Wm}^{-2} \mathrm{sr}^{-1} \mu \mathrm{m}^{-1}\right]$

$L_{\mathrm{gi}} \quad$ Global irradiance at the ith pixel, integrated from wavelength $\lambda_{1}$ to $\lambda_{2}\left[\mathrm{Wm}^{-2} \mathrm{sr}^{-1} \mu \mathrm{m}^{-1}\right]$

The strong annual dependency of the differences has the shape of a modified sinuous curve. In the hours around noon, the differences are highest, produced by a lower sun altitude and the long shadows. In summer, the differences are much smaller. Only in the morning and the evening hours (09:00 and 16:00), when the sun is even lower, the differences are lowest in winter. This is due to the strong increase in the percentage of diffuse radiation at very low sun altitudes as can be seen in Fig. 2.
The differences are lowest in winter which is due to the strong increase in the percentage of diffuse radiation at very low sun altitudes. At all times, the annual courses show a faint zigzag pattern. This pattern is produced by the $1-\mathrm{m}$ resolution of the city surface model. Each time, the curve slightly drops or rises, the modelled shadows from the buildings were extended or shortened about one pixel. Figure 3a shows the absolute mean difference (MAD) in percentage for the whole available city model, Fig. 3b shows the error for a selected area of Basel $(500 \times 500 \mathrm{~m})$, which is characterised by its dense housing. It is a larger area than the example in Fig. 2, and shall document how the results are changing for a specific type of urban buildings. For these figures, the rural aerosol model, visibility $23 \mathrm{~km}$, was used. The magnitude of the MAD strongly depends on the applied aerosol model. While the MAD is minimal for the urban $5-\mathrm{km}$ visibility model, it is maximal for highest visibility (no aerosol attenuation).

Table 1 shows the annual MAD for the three models for each hour. Input for the data is the whole city model. For the densely built up area, the values are 1.2-1.3 times higher than for the whole city area.

The strong spatial pattern of the urban fabrics produces a high standard deviation for the already-mentioned MADs. The standard deviations of the MAD in irradiation estimation have similar magnitudes to the averages. For example, the two annual courses of 09:00 and 16:00 show

Table 1 Absolute mean error (MAD) in irradiation (\%) estimation using the four different aerosol models for the whole urban area

\begin{tabular}{|c|c|c|c|c|c|c|c|c|}
\hline Time/visibility & 09:00 & $10: 00$ & $11: 00$ & $12: 00$ & 13:00 & $14: 00$ & $15: 00$ & $16: 00$ \\
\hline $5 \mathrm{~km}$ & 16.6 & 16.7 & 16.3 & 15.8 & 16.4 & 16.9 & 17.0 & 16.9 \\
\hline $23 \mathrm{~km}$ & 26.1 & 26.0 & 23.8 & 22.2 & 23.3 & 25.0 & 26.5 & 26.0 \\
\hline $50 \mathrm{~km}$ & 34.2 & 32.0 & 28.1 & 25.8 & 27.1 & 29.6 & 32.7 & 33.7 \\
\hline No aerosol attenuation & 49.0 & 40.6 & 34.3 & 31.0 & 32.6 & 36.2 & 41.8 & 49.0 \\
\hline
\end{tabular}

Annual mean values are given 
Table 2 Standard deviation of MAD in irradiation estimation (\%) using the three different aerosol models for the whole urban area

\begin{tabular}{|c|c|c|c|c|c|c|c|c|}
\hline Time/visibility & 09:00 & $10: 00$ & $11: 00$ & $12: 00$ & $13: 00$ & $14: 00$ & $15: 00$ & $16: 00$ \\
\hline $5 \mathrm{~km}$ & 13.4 & 14.8 & 15.4 & 15.4 & 15.9 & 15.7 & 14.9 & 13.5 \\
\hline $23 \mathrm{~km}$ & 22.2 & 25.0 & 25.5 & 25.1 & 25.8 & 25.8 & 24.9 & 22.1 \\
\hline $50 \mathrm{~km}$ & 29.7 & 31.8 & 31.3 & 30.4 & 31.1 & 31.6 & 31.6 & 29.3 \\
\hline No aerosol attenuation & 44.7 & 40.8 & 38.4 & 36.7 & 37.4 & 38.6 & 40.7 & 45.3 \\
\hline
\end{tabular}

Annual mean values are given

highest standard deviations in summer but lower values in winter. All other curves have two peak maximums in spring and autumn and show a little depression in summer. All curves stay below $29.1 \%$ for the whole area and below $30.2 \%$ for the densely built-up urban area during the whole year (rural aerosol model, visibility $23 \mathrm{~km}$ ). In the case of the 'no aerosol attenuation model', the numbers are $69.0 \%$, and $67.0 \%$ respectively.

Table 2 addresses the different results produced by the four aerosol models. The lowest standard deviations are found at the lowest visibility $(5 \mathrm{~km})$, the highest at the highest visibility (no aerosol attenuation); however, here the differences between the small densely built up area and the whole city model are very low, only the values for the whole city model are given.

In the preceding tables and figures, the absolute mean is considered for the estimation of the error. This means that negative differences are treated as positive values in the calculation of the mean. There are two main sectors, where highest differences occur. The first sector is where shaded pixels appear. There, the modelled irradiance is much lower than the irradiance on a horizontal plane. A second much smaller sector includes the inclined rooftops, which are almost perpendicular to an imaginary roof-sun line. There, very high intensities occur which are higher than the irradiance on a horizontal plane. A major part of the pixels show only very small differences. They include horizontal areas like unshaded streets, horizontal roofs and green parks.

The normal means of the differences (MD), including positive and negative pixels, are lower than the absolute means over the whole course of the year. The two extreme sectors already-mentioned in the preceding paragraph partly cancel out each other. The MD range, in the case of $23-\mathrm{km}$ visibility ranges from $11.1 \%(12.00)$ to $13.2 \%$ $(15: 00)$ for the whole area and from $23.9 \%$ (12.00) to $28.0 \%(15: 00)$ for the densely built-up urban area. The standard deviations range from 23.3 to $25.0 \%$ for the whole area and from 28.4 to $32.3 \%$ for the densely built-up urban area. These lower mean errors imply that if the area that represents a pixel is large enough, even though the standard deviations are higher, the differences might be small enough to be ignored.
The MD is calculated as follows:

$M D=\frac{1}{n} \sum_{i=1}^{n}\left(L_{g \_ \text {mean }}-L_{g i}\right)$

This consideration leads to the next step of this analysis: a spatial aggregation series was produced to find the error, which is dependent on the pixel resolution. The spatial resolution of the original image is $1 \mathrm{~m}$. Only integer multiples of the original resolution were used for the aggregation procedure. The aggregated images were downscaled in $1-\mathrm{m}$ steps up to $100-\mathrm{m}$ resolution. No effects of nonlinearity were considered in this process.

The MD (not the MAD) of the whole city surface model does of course not change with decreasing resolution. Figure 4 shows the MD averaged for the whole year at 11:00, 12:00, 13:00 and 14:00 hours. These are the hours where the sun position is still high enough that the diffuse part of the incoming solar radiation stays small. The MD stays at $23 \%$ for all the resolutions for the atmosphere with a visibility of $23 \mathrm{~km}$.

The standard deviation of the annual mean is higher and ranges from $27.9 \%$ at $2-\mathrm{m}$ resolution to $5.0 \%$ at $100-\mathrm{m}$ resolution. It decreases continuously while the pixel resolution gets coarser; however, the rate of decrease also gets lower with coarser pixel resolution. The annual course of the standard deviations of the MD reflects the position of

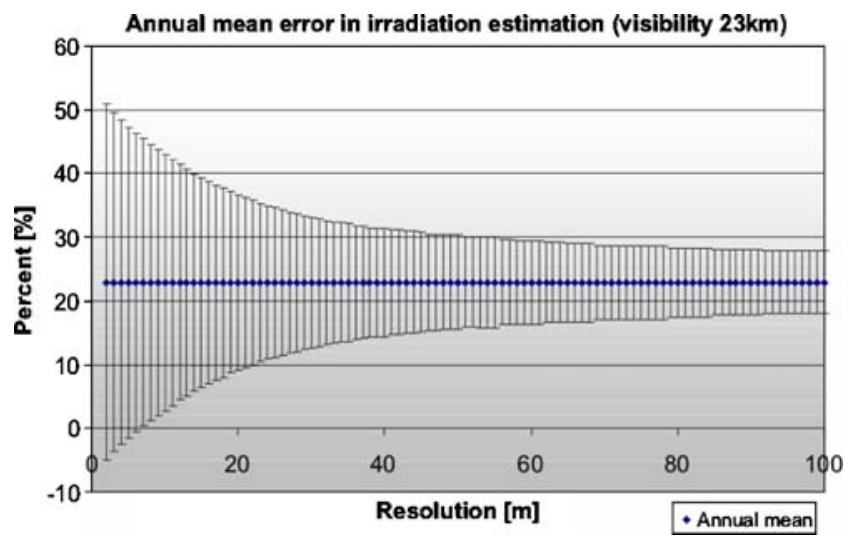

Fig. $4 \mathrm{MD}$ of irradiation estimation in percent (\%) of the irradiance on a horizontal plane (Mean is from the hours from 11:00 to 14:00). Visibility is $23 \mathrm{~km}$ 

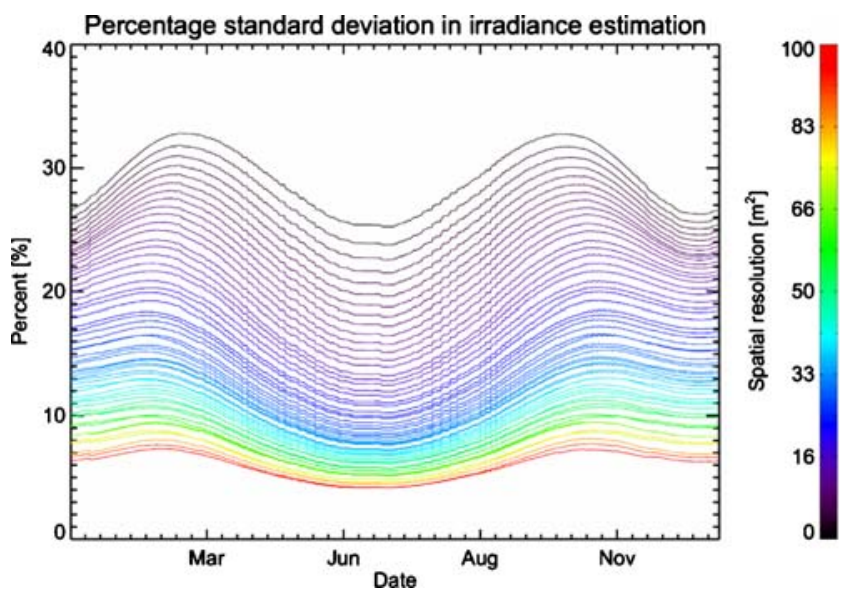

Fig. 5 Standard deviation of the MD in irradiation estimation in percent $(\%)$ of the irradiance on a horizontal plane of the small densely built-up urban area. (Mean is from the hours from 11:00 to 14:00.) Visibility is $50 \mathrm{~km}$

the sun towards the houses. While in summer and winter the standard deviations are relatively small, they increase in spring and autumn. Similarly, the standard deviations decrease towards noon. Figure 5 shows the standard deviation of the MD in irradiation estimation in percent of the irradiance on a horizontal plane during the annual course for all calculated points in time from 11:00 to 14:00 and for different resolutions for the rural aerosol model, $50 \mathrm{~km}$ visibility. As already discussed, the standard deviations decrease with the spatial resolution getting coarser. The standard deviations level off at a spatial resolution of about $50 \mathrm{~m}$. Resolutions coarser than $50 \mathrm{~m}$ cease to decrease in any significant amount.

\subsection{Estimation of urban reflectance}

Furthermore, the local albedos from the land use classes were compared to modelled regional albedos. These regional albedos were computed reversing the process of creating the reflection image; they are the ratio between the

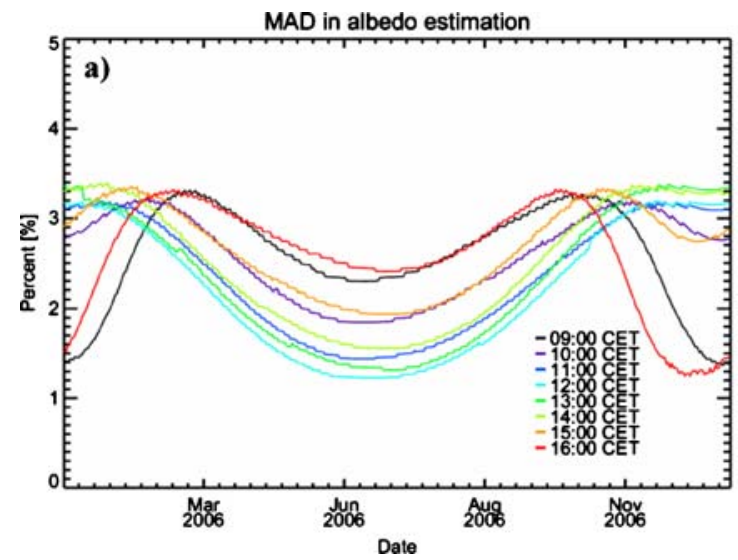

calculated reflected irradiance and one single value for the global irradiance - the irradiance on a horizontal plane. By computing the difference between the two albedos-local albedo minus modelled albedo-the error in albedo estimation can be evaluated.

It was found, that the MAD in albedo estimation ranges from 1.5 to $4.1 \%$ for the whole area and 1.7 to $5.3 \%$ for the densely built-up urban area, calculated for all times and days of the year and for all four atmospheric models. These values are relatively high, as the average albedo of the area of the city model is only $10.3 \%$. This means that in the worst case scenario, the shading effect reduces the urban albedo by almost half of its value. It has to be considered that these percentages are albedo values, and not percentages of the original albedo - otherwise they would be considerably higher. Figure 6 shows the MAD in albedo estimation for the whole city surface model and from the selected densely built-up area for the rural model, $23 \mathrm{~km}$ visibility.

The annual means of the MAD in albedo estimation are given in Tables 3 and 4 . They reflect the same pattern as the MAD of the irradiance calculation: the better the visibility, the higher the error in the albedo estimation. In the small densely built-up area, the errors are again higher compared to the whole city area.

The standard deviations, also in Tables 3 and 4, are almost as high as the MAD and reflect the high spatial variability of the urban fabrics. The MDs, including positive and negative pixels, over the whole course of the year are much lower. In the case of the $23-\mathrm{km}$ visibility model, they range from $1.68 \%(12: 00)$ to $1.91 \%(16: 00)$ for the whole city area and $2.20 \%(12: 00)$ to $2.59 \%(17: 00)$ for the densely built-up area. However, standard deviations of MD show a significant annual and daily course as found for the MD of the irradiances.

Both the MAD and most of all the standard deviations decrease with a coarser resolution. The behaviour of the MAD over the course of the year is dependent on the

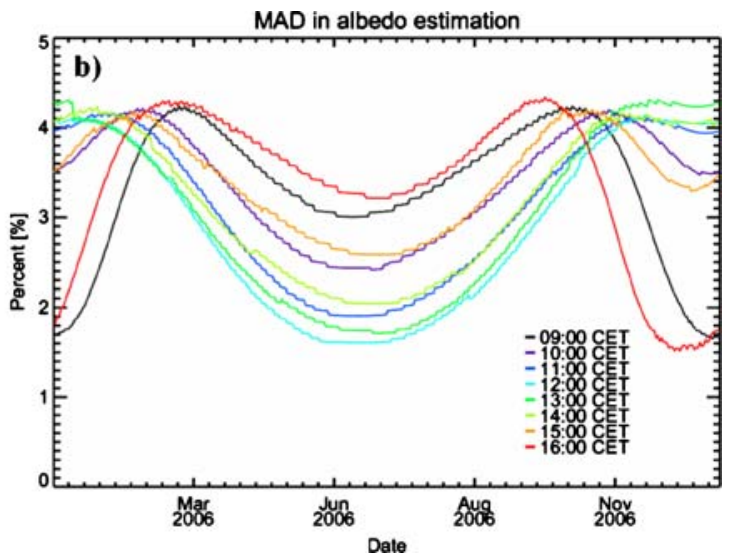

Fig. 6 MAD in albedo estimation a from the whole city surface model, b from a selected densely built-up area. Visibility is $23 \mathrm{~km}$ 
Table 3 MAD in albedo estimation (\%) using the four different aerosol models for the whole urban area

\begin{tabular}{|c|c|c|c|c|c|c|c|c|c|}
\hline Time/visibility & Statistical measure & 09:00 & 10:00 & $11: 00$ & $12: 00$ & $13: 00$ & $14: 00$ & $15: 00$ & $16: 00$ \\
\hline $5 \mathrm{~km}$ & MAD & 1.54 & 1.55 & 1.52 & 1.48 & 1.55 & 1.60 & 1.61 & 1.59 \\
\hline $23 \mathrm{~km}$ & MAD & 2.59 & 2.59 & 2.36 & 2.21 & 2.34 & 2.51 & 2.67 & 2.59 \\
\hline $50 \mathrm{~km}$ & MAD & 3.50 & 3.26 & 2.85 & 2.62 & 2.77 & 3.03 & 3.36 & 3.46 \\
\hline No aerosol attenuation & MAD & 5.2 & 4.2 & 3.5 & 3.2 & 3.4 & 3.8 & 4.4 & 5.2 \\
\hline $5 \mathrm{~km}$ & $\mathrm{SD}$ & 1.26 & 1.39 & 1.45 & 1.46 & 1.55 & 1.53 & 1.45 & 1.31 \\
\hline $23 \mathrm{~km}$ & $\mathrm{SD}$ & 2.35 & 2.63 & 2.61 & 2.55 & 2.66 & 2.71 & 2.68 & 2.38 \\
\hline $50 \mathrm{~km}$ & SD & 3.44 & 3.48 & 3.29 & 3.15 & 3.27 & 3.38 & 3.53 & 3.41 \\
\hline No aerosol attenuation & SD & 5.6 & 4.6 & 4.1 & 3.9 & 4.0 & 4.2 & 4.7 & 5.7 \\
\hline
\end{tabular}

Annual mean values are given. $S D$ standard deviation

aerosol model. While the urban model (visibility $5 \mathrm{~km}$ ) shows a two-peak maximum in early spring and late autumn, the other models have highest differences in winter. The lower differences in winter in the urban aerosol model are due to the high proportion in diffuse irradiance. It diminishes the distinction between sunlit and shaded pixels. This high proportion is maximal in winter and superimposes the effect of shading. Also, the differences between the various resolutions are almost zero for the urban aerosol model, while it is maximal for the 'no aerosol attenuation' model (see Fig. 7). In summer, when the MAD is lowest in all cases, it stabilizes at around $2 \%$. The smoothing effect of the decreasing pixel resolution is best visible in wintertime.

The standard deviations show an undulating pattern, with maximum differences in spring and autumn, except for the 'no aerosol attenuation' model, where the highest differences occur in winter. All models show lower differences with coarser resolution, whereas this effect is as expected to be the lowest for the urban aerosol model (visibility $5 \mathrm{~km}$ ). For the resolution of $100 \mathrm{~m}$, the standard deviations are lower than $1 \%$ in all cases (Fig. 8).

\section{Summary and conclusions}

Errors in the estimation of irradiance and albedo in an urban area were estimated based on a raster city model and
MODTRAN runs. It was found, that the urban fabrics impose a great obstacle in estimating urban albedo from space, due to its diversification in global irradiance. A densely built-up urban area exhibits higher possible errors in the estimation of irradiance and albedo than a general urban area. Therefore, automatically an error arises when estimating the albedo from satellite images with a methodology that does not include any correction for the spatial distribution of the global irradiance.

Furthermore, it was found that the percentage of diffuse irradiance of the global irradiance plays an important role in the magnitude of the error. The higher the part of the diffuse irradiance, the lower is the projected error in the calculation of the albedo. Disregarding the difficulties in correcting satellite images for the atmospheric effects (modelling of path irradiance and transmissivity), it is preferable to estimate the urban albedo on a less clear, but still sunny day, as the diffuse irradiances dilute the sharp contrasts of the shadings.

Due to the shading, resulting from the urban geometry, it is optimal to use images, acquired at a time of highest possible sun-elevation angles. Therefore, the remaining error in albedo estimation in summer is much lower than in winter. In the basic case of 1-m resolution, the MAD (mean absolute difference) in albedo estimation was found to be in the range of 1.5 to $7.9 \%$ for the densely built-up urban area, as calculated from 11:00 to 14:00 hours each day of the

Table 4 Absolute mean error in albedo estimation (\%) using the four different aerosol models for the densely built-up urban area

\begin{tabular}{|c|c|c|c|c|c|c|c|c|c|}
\hline Time/Visibility & Statistical measure & 09:00 & $10: 00$ & $11: 00$ & $12: 00$ & $13: 00$ & $14: 00$ & $15: 00$ & $16: 00$ \\
\hline $5 \mathrm{~km}$ & MAD & 1.93 & 1.97 & 1.95 & 1.90 & 1.98 & 2.02 & 2.04 & 2.02 \\
\hline $23 \mathrm{~km}$ & MAD & 3.32 & 3.39 & 3.14 & 2.90 & 3.02 & 3.02 & 3.42 & 3.37 \\
\hline $50 \mathrm{~km}$ & MAD & 4.5 & 4.3 & 3.8 & 3.5 & 3.6 & 3.9 & 4.3 & 4.5 \\
\hline No aerosol attenuation & MAD & 6.6 & 5.6 & 4.7 & 4.2 & 4.8 & 4.8 & 5.6 & 6.6 \\
\hline $5 \mathrm{~km}$ & $\mathrm{SD}$ & 1.25 & 1.42 & 1.51 & 1.52 & 1.59 & 1.58 & 1.50 & 1.31 \\
\hline $23 \mathrm{~km}$ & SD & 2.34 & 2.65 & 2.69 & 2.63 & 2.74 & 2.79 & 2.72 & 2.32 \\
\hline $50 \mathrm{~km}$ & SD & 3.5 & 3.5 & 3.4 & 3.3 & 3.4 & 3.5 & 3.6 & 3.3 \\
\hline No aerosol attenuation & SD & 5.9 & 4.7 & 4.3 & 4.0 & 4.1 & 4.4 & 4.8 & 5.7 \\
\hline
\end{tabular}

Annual mean values are given. $S D$ standard deviation 

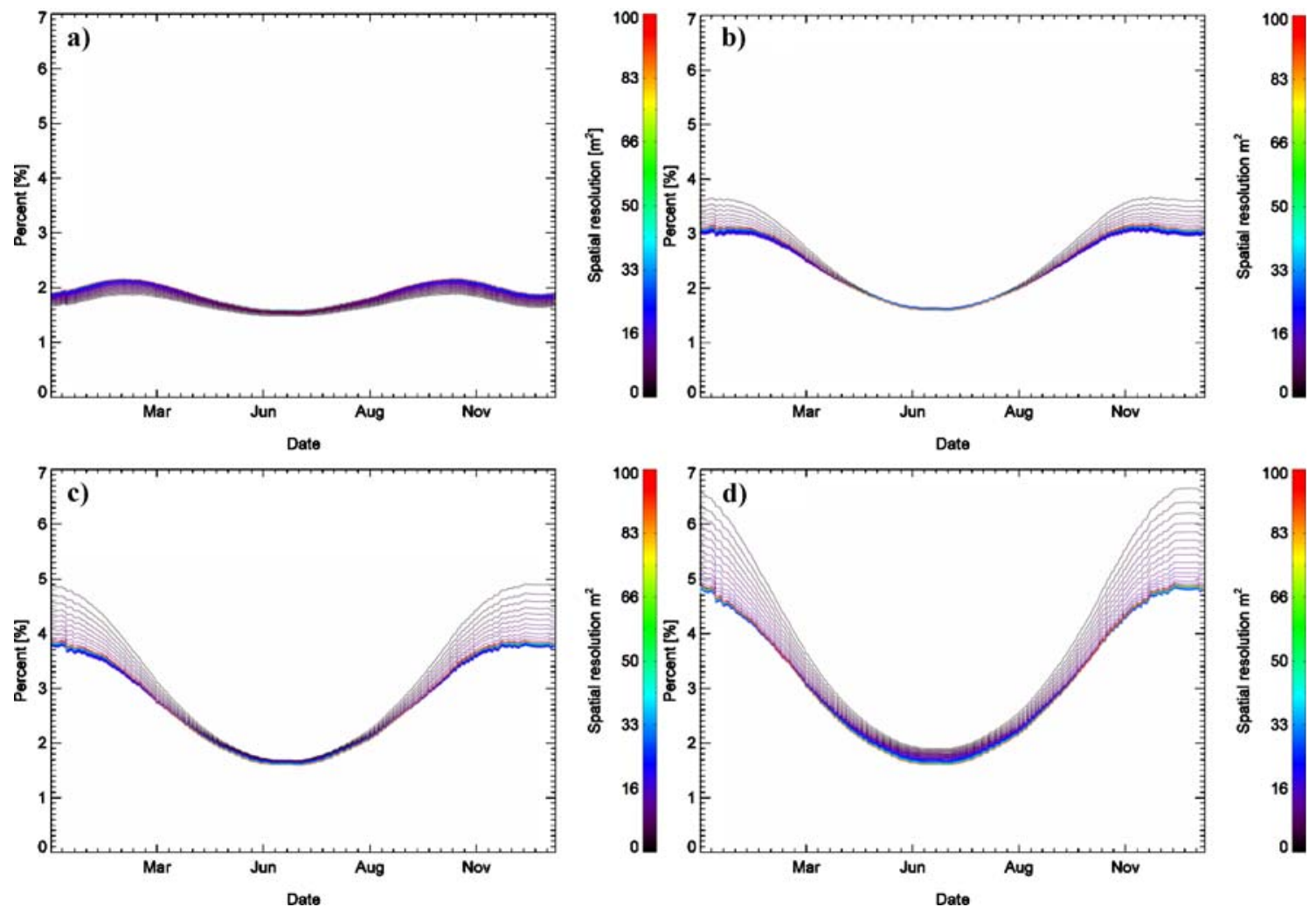

Fig. 7 MAD in albedo estimation from a selected densely built-up area. a Urban aerosols, visibility $5 \mathrm{~km}$, b rural aerosol, visibility $23 \mathrm{~km}$, c only tropospheric aerosols, visibility $50 \mathrm{~km}$, $\mathbf{d}$ no aerosol attenuation
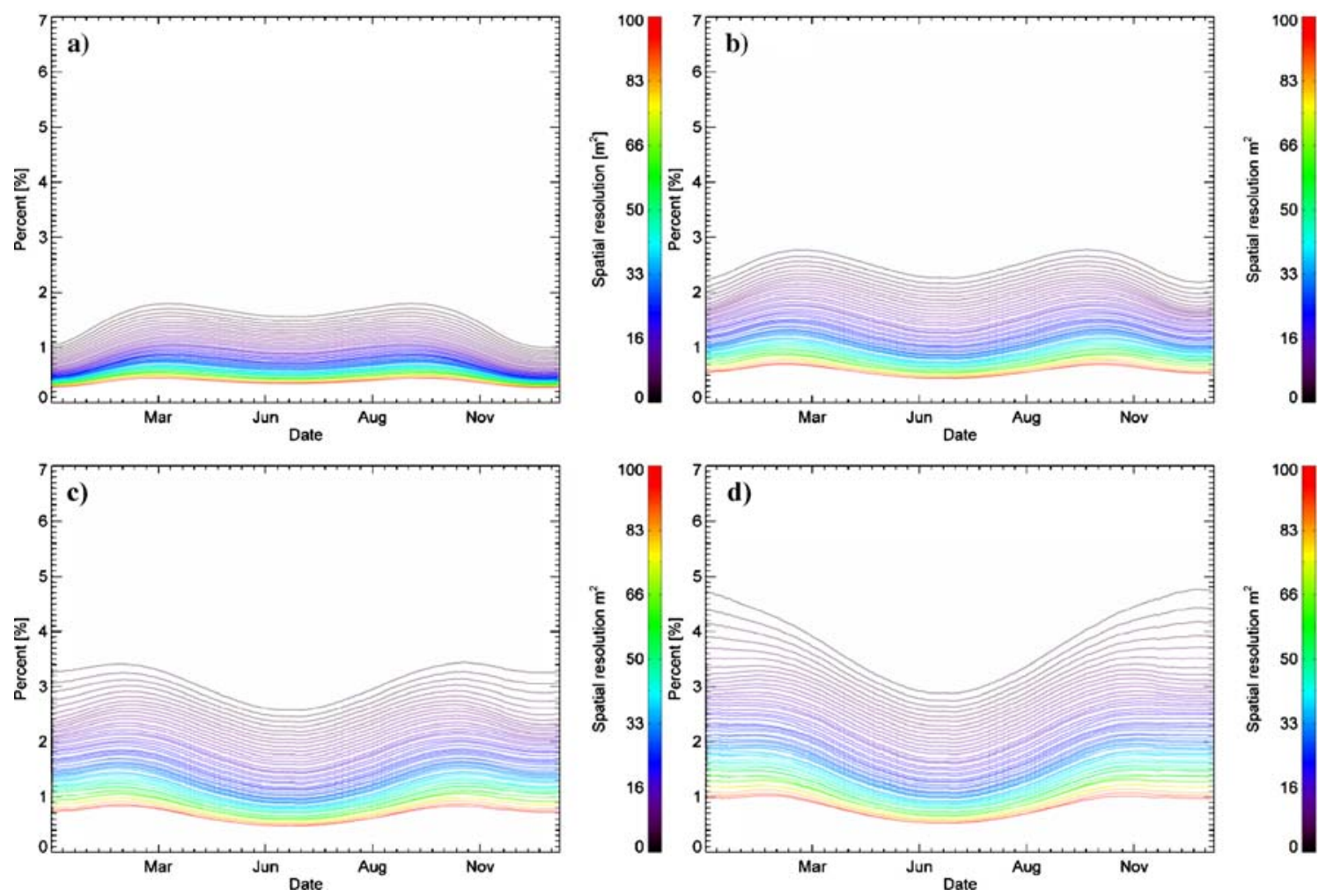

Fig. 8 Standard deviation of MAD in albedo estimation from a selected densely built-up area. a Urban aerosols, visibility $5 \mathrm{~km}$, b rural aerosol, visibility $23 \mathrm{~km}$, c only tropospheric aerosols, visibility $50 \mathrm{~km}$, d no aerosol attenuation 
year for all four atmospheric models. Considering that the assumed average albedo is $10.3 \%$ only, the MAD can be higher than half of the albedo value itself. These differences decrease with coarser spatial resolution, as very strong illuminated surfaces such as sun-direction declined roofs compensate for part of the error resulting from the shaded surfaces. In an area where only flat roofs occur, this effect would not be present. In the case of the 100-m aggregated pixels, the MAD in albedo estimation in the densely builtup urban area was found to be much lower-in the range of 0.4 to $4.2 \%$ from 11:00 to 14:00 hours each day of the year for all four atmospheric models.

Acknowledgements We thank the Federal Office of Meteorology and Climatology (MeteoSwiss) for providing us the irradiation data of the stations Davos and Payerne, Switzerland. This research was conducted partly at ESA-ESTEC, Noordwijk, The Netherlands. The authors appreciate the kind support of Michael Berger. This project was funded by the Swiss Science Foundation with grant No. 200021-109472.

\section{References}

Aida M (1982a) Urban albedo as a function of the urban structure: a model experiment. Boundary-Layer Meteorol 23(4):405-413

Aida M, Gotoh M (1982b) Urban albedo as a function of the urban structure: a two-dimensional numerical simulation. BoundaryLayer Meteorol 23:416-424

Berk A, Anderson GP, Bernstein LS, Acharya PK, Doethe H, Matthew MW, Adler-Golden SM, Chetwynd JH, Richtsmeister SC, Pukall B, Allred CL, Jeong LS, Hoke ML (1999) MODTRAN 4 radiative transfer modeling for atmospheric correction. SPIE Proceeding, Optical Spectroscopic Techniques and Instrumentation for Atmospheric and Space Research III, vol 3756, Denver CO, July 1999, SPIE, Bellingham, WA, USA, 6 pp

Brest CL (1987) Seasonal albedo of an urban/rural landscape from satellite observations. J Appl Meteorol 26(9):1169-187

Christen A, Vogt R (2004) Energy and radiation balance of a central European city. Int J Climatol 24:1395-1421

Chrysoulakis N (2003) Estimation of the all-wave urban surface radiation balance by use of ASTER multispectral imagery and in situ spatial data. J Geophys Res 108(D18):10

Chrysoulakis N, Diamandakis M, Prastacos P (2004) GIS based estimation and mapping of local level daily irradiation on inclined surfaces. In: Toppen F, Prastacos P (eds) Proceedings of the 7th AGILE Conference on Geographic Information Science, Crete, 2004, pp 587-597

Dozier J, Bruno J, Downey P (1981) A faster solution to the horizon problem. Comput Geosci 7:145-151

Erbs DG, Klein SA, Duffie JA (1982) Estimation of the diffuse radiation fraction for hourly, daily and monthly average global radiation. Sol Energ 28(4):293-304

Frey C, Rigo G, Parlow E (2007) Urban radiation balance of two coastal cities in a hot and dry environment. Int J Remote Sens 28 (12):2695-2712

Hafner J, Kidder SQ (1999) Urban heat island modeling in conjunction with satellite-derived surface/soil parameters. J Appl Meteorol 38(4):448-465
Halthore RN, Schwartz SE (2000) Comparison of model-estimated and measured diffuse downward irradiance at surface in cloudfree skies. J Geophys Res 105(D15):20165-20177

Henzing JS, Knap WH, Stammes P, Apituley A, Bergwerff JB, Swart DPJ, Kos GPA, ten Brink HM (2004) Effect of aerosols on the downward shortwave irradiances at the surface: Measurements versus calculations with MODTRAN4.1. J Geophys Res 109 (D14204)

Hofierka J, Śúri M (2002) The solar radiation model for Open source GIS: implementation and applications. In: Proceedings of the Open source GIS-GRASS users conference 2002, Trento, Italy, September 2002, pp 11-13

Iqbal M (1983) An introduction to solar radiation. Academic, New York

Kondo A, Ueno M, Kaga A, Yamaguchi K (2001) The influence of urban canopy configuration on urban albedo. Boundary-Layer Meteorol 100(2):225-242

Liu BYH, Jordan RC (1963) The long-term average performance of flatplate solar energy collectors. Sol Energ 7:53

Maxwell EL (1987) A quasi-physical model for converting hourly global horizontal to direct normal insolation. SERI (Solar Energy Research Institute), Golden, CO, USA

NASA (2007a) ASTER Surface Reflectance/ Radiance VNIR/SWIR Product. Jet Propulsion Laboratory, California Institute of Technology, Pasadena, CA, USA. http://asterweb.jpl.nasa.gov/ content/03_data/01_Data_Products/release_aster_surface reflectance.htm. Cited 15 June 2007

NASA (2007b) Landsat 7 Science Data Users Handbook. NASA, Washington, DC. http://landsathandbook.gsfc.nasa.gov/ handbook.html. Cited 15 June 2007

Parlow E (1996) Correction of terrain controlled illumination effects in satellite data. In: Parlow E (ed) Progress in environmental research and applications. Balkema, Rotterdam, pp $139-145$

Parlow E (1998) Net radiation of urban areas. In: Gudmandsen P (ed) Future trends in remote sensing. Balkema, Rotterdam, pp 221226

Rigo G, Parlow E (2007) Modelling the ground heat flux of an urban area using remote sensing data, Theor Appl Climatol 90:185-199

Rotach MW, Vogt R, Bernhofer C, Batchvarova E, Christen A, Clappier A, Feddersen B, Gryning S-E, Martucci G, Mayer H, Mitev V, Oke TR, Parlow E, Richner H, Roth M, Roulet YA, Ruffieux D, Salmond J, Schatzmann M, Voogt JA (2005) BUBBLE: an urban boundary layer meteorology project. Theor Appl Climatol 81:231-261

Sailor DJ (1995) Simulated urban response to modifications in surface albedo and vegetative cover. J Appl Meteorol 34:1694-1704

Sailor DJ, Fan H (2002) Modeling the diurnal variability of effective albedo for cities. Atmos Environ 36(4):713-725

Schläpfer D, Odermatt D (2006) MODO User Manual, Version 3. ReSe Applications, Wil, Switzerland

Schwander H, Mayer B, Ruggaber A, Albold A, Seckmeyer G, Koepke P (1999) Method to determine snow albedo values in the ultraviolet for radiative transfer modelling. Appl Opt 38:38693875

Small C (2005) A global analysis of urban reflectance. Int J Remote Sens 26(4):661-681

Soler MR, Ruiz C (1994) Urban albedo derived from direct measurements and Landsat $4 \mathrm{TM}$ satellite data. Int J Climatol 14:925-931

Taha H (1997) Urban climates and heat islands: albedo, evapotranspiration, and anthropogenic heat. Energ Build 25(2):99-103 